\title{
Spatial and temporal real-time ambient Carbon Monoxide ward-wise mapping for BENGALURU City
}

\author{
Rajesh Gopinath ${ }^{1}{ }^{*}$, Monica Krishna G.M. ${ }^{1}$, Pratik Kumar Sinha ${ }^{1}$, Nitish \\ Kumar $^{1}$ and Deepak Tripathi ${ }^{1}$ \\ ${ }^{1}$ Department of Civil Engineering, BMS Institute of Technology and Management, Bengaluru 64, \\ India \\ * Correspondence: dr.rajeshgopinathnair@gmail.com
}

Keywords: Bengaluru, Violations, Planning, Carbon, Urban

\begin{abstract}
Longevity in life span of city dwellers depends upon the quality of ambient air, which is often compromised due to urbanization. In this context, since independence, Bengaluru has rampantly grown with elevated air and automobile pollution levels. Ambient Carbon Monoxide [CO], which is considered to be the most dangerous criteria air pollutant, however has insufficient research/literature for the city of Bengaluru. To plug this gap, the pre-sent study engages a detailed examination for Temporal and Spatial Map-ping variation of Ambient 'CO' concentration in different wards of Bengaluru using calibrated Digital 'CO' sensor. The methodology involved primarily an intensive literature review followed by reconnaissance survey for fixation of monitoring stations about each 'ward'. Further at these observatories, extensive primary data collection was ensued at periodic and regular intervals. The objective serves to delineate the most critical and non-critical places in Bengaluru to incorporate remedial measures. Startling $400+$ violations with potential of triggering congestive heart failure, impaired performance in time discrimination, shortened time to angina response and vigilance decrement were observed. Sustainability measures conclude the study.
\end{abstract}

\section{Introduction}

As one among the fastest growing megacity, Bengaluru (Figure I), has quite sporadically grown about all directions (Vrinda T. 2018; F. Samana, 2012; Dipak D.G. 2017), with rampant urbanization resulting in various environ-mental concerns (Vinod B.R., 2020; Aftab Jahan Begum, 2021). The major issue however remains to be progression of air pollution and deteriorating Air Quality index, which is majorly contributed by Automobile emissions (Balasubramanya, 2017). The vehicular count of Bengaluru aided by the absence of an effective-planned public transportation is growing multifold with several lakhs of private vehicles donning the city's landscape (Sachin S., 2020; P.R. Bhanumurthy et al. 2014, Vijayalakshmi Akella et al. 2015).

As a definite outcome Carbon Monoxide [CO], a colorless, odorless and tasteless gas. It is hence considered to be the most dangerous criteria ambient air pollutant (A.J. Begum et al. 2014; Aftab J.B. et al. 2017). Increased levels of $C O$ reduce the quantum of oxygen attached by hemoglobin in blood, resulting in failure of vital organs such as the brain and the heart. People with heart problems are likely to suffer from more frequent and longer angina attacks, with greater risk of heart attack (Raub J.A. et al. 2000). Occupational Safety and Health Administration (O.S.H.A., 2012) and the National Institute for Occupational Safety and Health (N.I.O.S.H., 2014), prescribes 35 ppm as an 8-hour Time weighted Average. 
United States Environment Protection Agency (US.E.P.A. 2011) and World Health Organization (W.H.O., 2000) recommend the exposure limit for 8 hours at 9 ppm and maximum of 1 hour for 35ppm.

Polluted metropolitan cities including Bengaluru often exceed the afore-mentioned thresholds, thereby increasing incidence of health issues. Yet archived observations are not publicly available (Y. Lokesh and Gopinath R., 2017; Rajesh Gopinath et al. 2017). Also when compared with all air pollutants, no major exhaustive studies have been carried out in Bengaluru on real-time basis to explore its impending health threats as an inadvertent outcome of rise in petrol engine vehicles. Most researches on urban outdoor air pollution have often focused mostly on oxides of Nitrogen and Sulphur (Kanakiya et al. 2015). There has been a dearth of research on CO levels and also the studies were restricted to a smaller number of sample size and as well limited by the location attributes (Suryati et al. 2017; Harinath et al. 2010). Hence, no research has managed to cover a vast area and thereby fail with respect to real-time validation. The present study was incepted to plug this gap in research and understand the impending, inadvertent and direct health threats of $\mathrm{CO}$. The major objective of this research encompasses determination of Temporal variation across all wards of Bengaluru using Digital CO sensor. This is followed by Spatial Mapping and delineation of the most critical and non-critical stations.

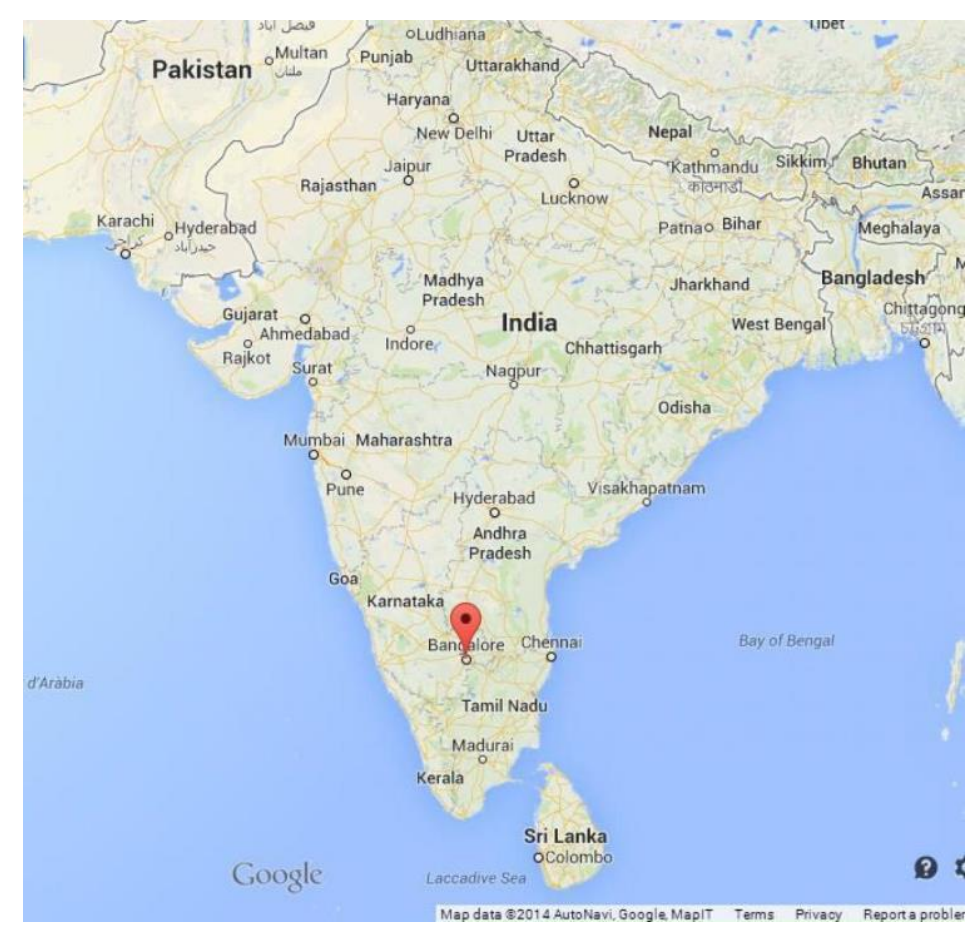

Figure.1. Political Map of India, depicting Bengaluru within State of Karnataka. (https://maps-bangalore.com/bengaluru-india-map)

\section{Experimental Methodology}

A key objective of the research primarily involved comparison of the CO levels about all the observatories. Monitoring of ambient $\mathrm{CO}$ levels was accomplished on weekdays across all the 198 wards of Bengaluru as represented in Figure 2. Strategic observatories i.e. prolific traffic junctions within wards were identified on the basis of geographical location), topography, political boundaries \& essential land-use patterns. While Figure 3 showcases geo-graphical location of each observatory, Figure 4 highlights their land-use 
pattern. The study was spread over a period of five months (encompassing both winter and summer seasons) from November 2019 to May 2020.The study was carried out with the assumption that the $\mathrm{CO}$ concentration would be more or less uniform on weekdays due to similar vehicular density, and could vary during weekends and holidays. Daily variation was monitored at 'four' observatories simultaneously on each day keeping in mind the land-use patterns. The monitoring was carried out with aid of a 'calibrated' digital CO meters possessing Stabilized Electrochemical Gas-specific sensor that was capable of detecting concentrations between 0 to $1000 \mathrm{ppm}$. Supported by data loggers with USB Interface, the device could store data up to 32,000 Measurements. The 11 hours continuous and simultaneous monitoring with precautions to eliminate outliers was restricted / programmed and engaged at half an hour interval from 7:30 AM to 6:30 PM.

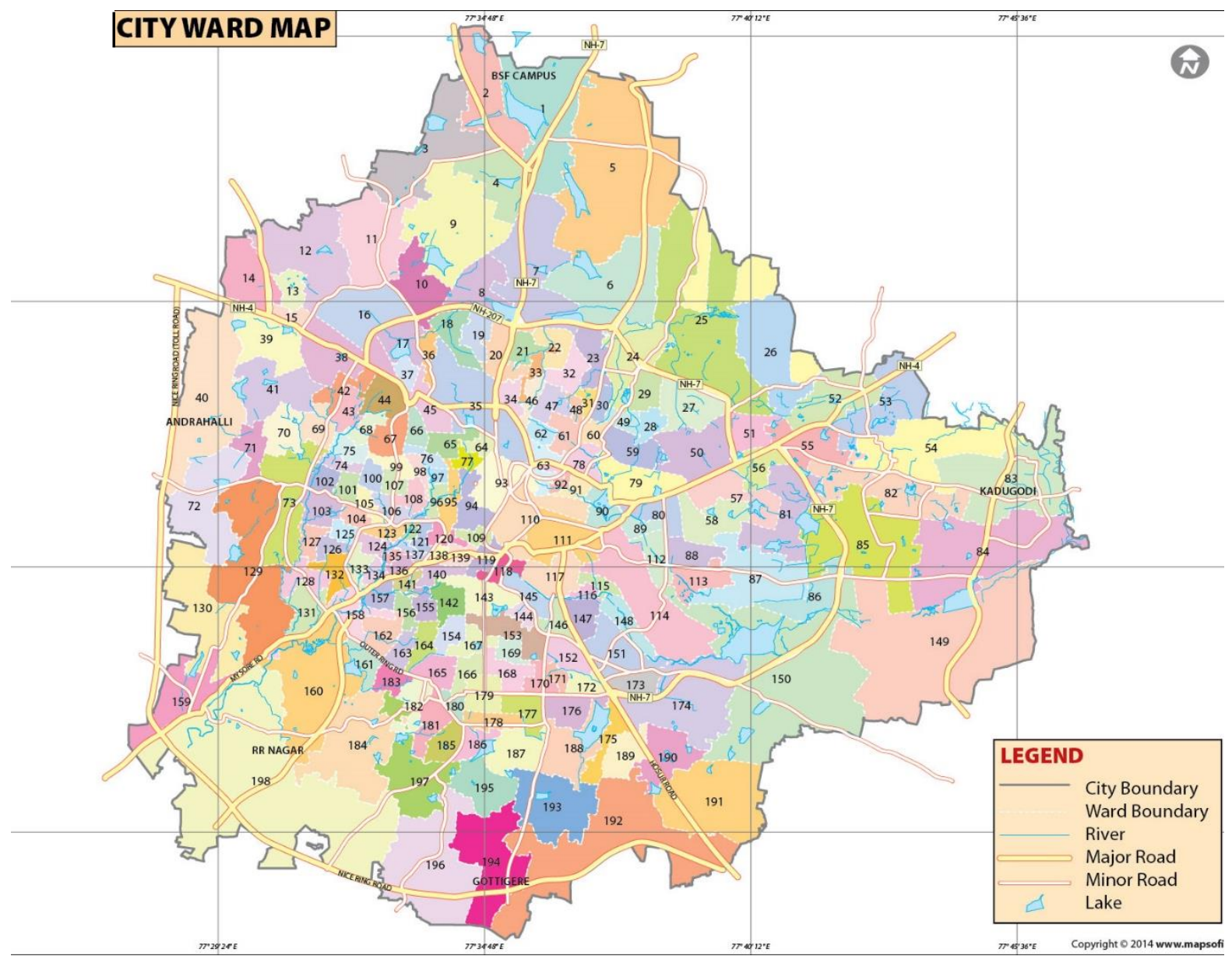

Figure.2. Political Map of Bengaluru, depicting 198 wards (https://www.mapsofindia.com/custom-maps/city-ward-boundary-map.html) 


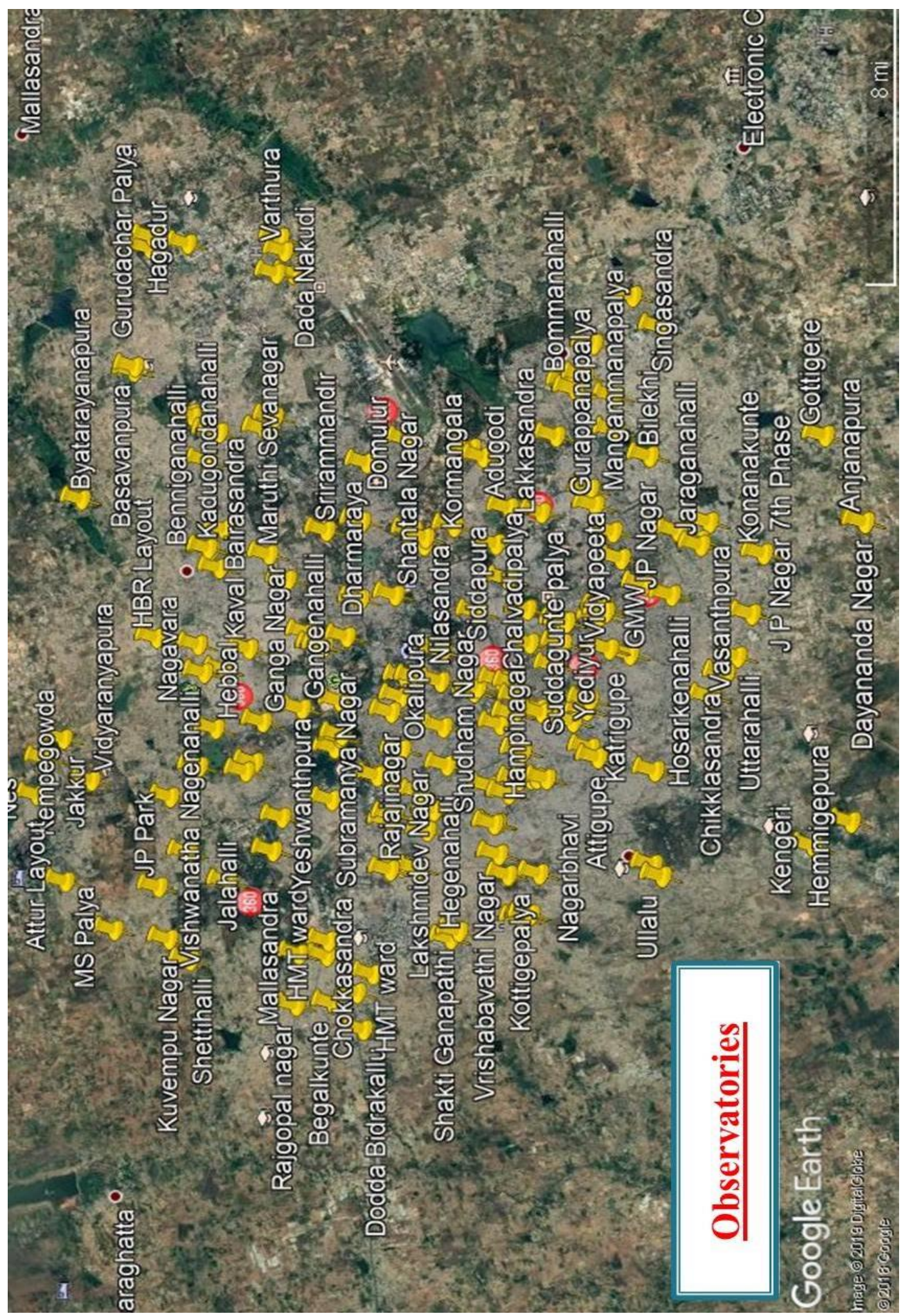




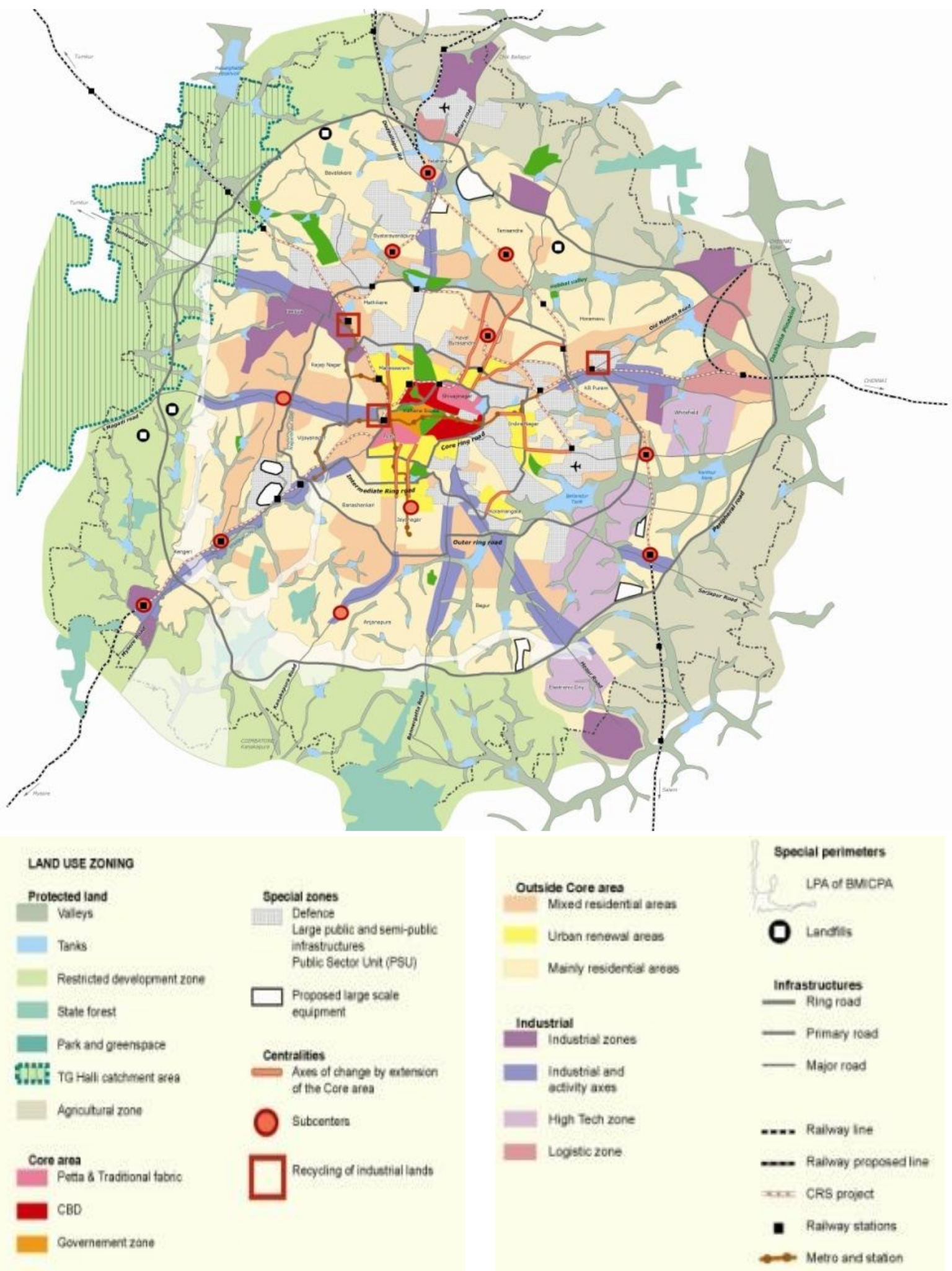

Figure 4. Land-use pattern of Bengaluru.

(https://affordablehousing.live/bangalore-master-plan-2015.html)

The sensors were placed at a height of $1.2-1.5 \mathrm{~m}$ from ground level in accordance with World Meteorological Organization norms (T.R Oke, 2006). The criteria air pollutant data collection was carried out at junctions/signals, wherein the probability of CO levels being highest was more frequent due to idling conditions of vehicles. The elaborate exercise would result in identification and computation of 'maximum', 'minimum' and 
'mean' ambient CO levels. 'Exposure-limit' was further compared and consulted with norms of O.S.H.A., E.P.A., W.H.O. and N.I.O.S.H. Further, delineation of the most critical and non-critical places in Bengaluru was achieved for identification and recommendation of corrective and preventive measures with respect to town planning.

\section{Results and Discussions}

The major causes observed for rising levels of ambient $\mathrm{CO}$ could be linked with a wide array of cross-linked and independent factors. These include office timings peaking vehicular density, reduced road width, movement of older vehicles, greater idling time due to traffic congestion, lack of strategic traffic signals, absence of monitoring by traffic policemen, proximity to high prolific areas and uphill paved roads, non-switching of engines at red signals, plying of private vehicles, single lane road handling double lane traffic, authorized and illegal parking of vehicles on sides of road crunching up motor-able space, road repair works etc. The most general trend observed for daily monitoring at all observatories as the day progressed was that the $\mathrm{CO}$ levels were increasing steadily after 8 AM. However between 12 to 4 PM the levels were found to slightly dip, before rising again up from 4 to 6 PM and beyond on account of vehicular movement of users returning to their residences. While this was a general trend, in commercial areas the peak was based on their selling times and continued to late evening hours. The same can be observed in Figure 5.

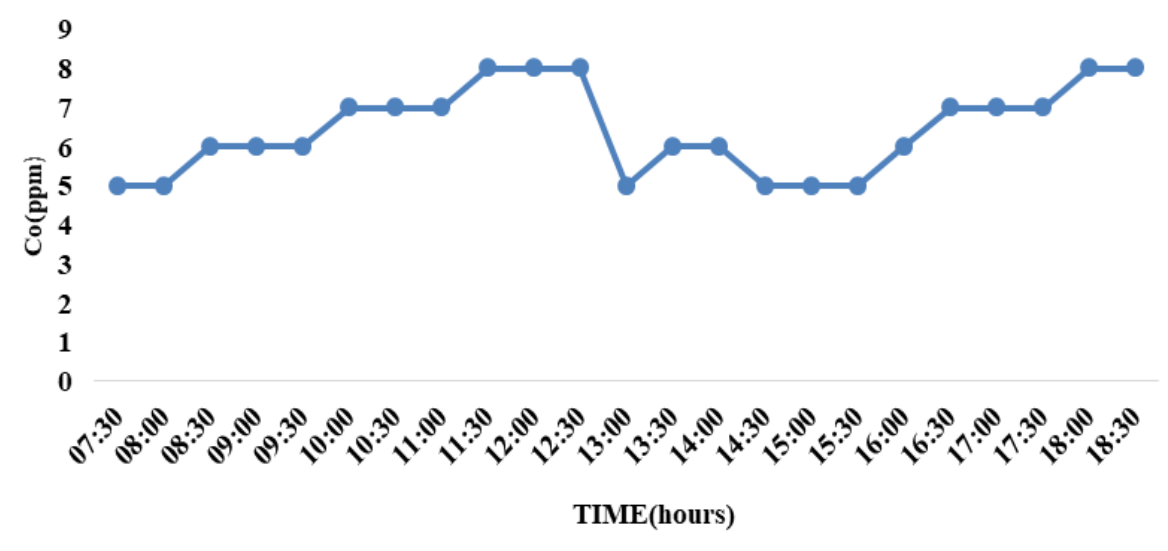

Figure 5. Sample Chart depicting the Hourly Variation of Carbon Monoxide levels at Shivaji Nagar - a Commercial Area, on a Random Day.

The generic trend shows lesser-to-moderate concentrations about land-uses such as in Public Green Spaces and Residential areas, as presented in Figure 6. The higher-to-severe levels were predominant in Commercial and Industrial zones, as can be observed from Figure 7. While the previous Charts were rep-resenting hourly variation about a specific observatory, Figure 8 divulges the significance of land-use patterns upon CO levels. Simultaneous hourly monitoring for variation of CO across Wards 41, 139, 122 and 139 had unveiled that Industrial and Commercial spaces were prone to elevated CO levels. This was on account of more private vehicles and reduced usage of public transport system. For observatories near Public Green Spaces, the entry timings, proximity and expanse had contributed to the cause rising and dipping CO levels. Similar rationale was applied to Residential areas i.e. standard of living, planned-unplanned streets in terms of surfacing and width hampering cruise movement and enhancing idling time, private vehicle density, proximity to places of interest such as temples, NH/SH and practice of car-pooling by residents. This discussion is also supported by the 
representation of Figure 9, which depicts wide variation in the hourly arithmetically averaged mean values of CO for all the 198 wards. The representation clearly presents diversity across all the wards highlighting the afore mentioned causes and non-uniformity about all wards w.r.t. observatories. Most observatories possessed hourly average for $\mathrm{CO}$ intensity $>2 \&<9$ ppm.

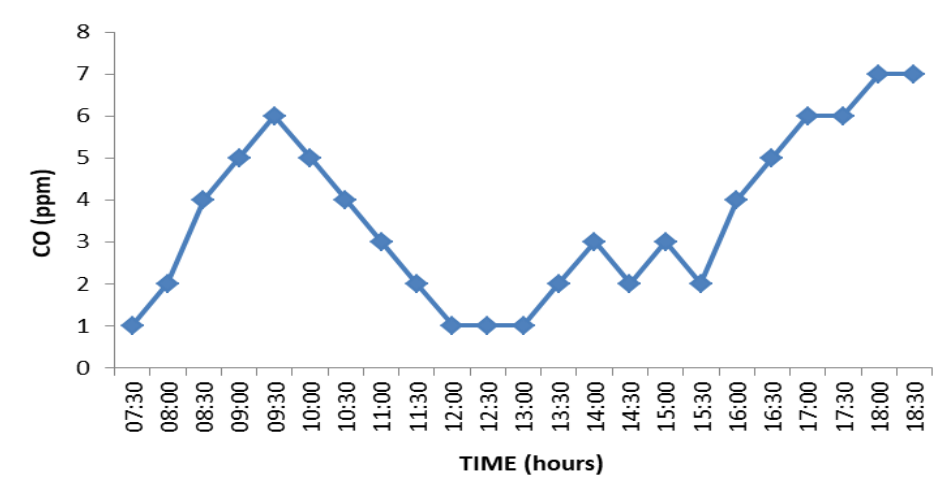

Figure 6. Sample Chart depicting the Hourly Variation of Carbon Monoxide levels at Kempapura Agrahara - a Residential Area, on a Random Day.

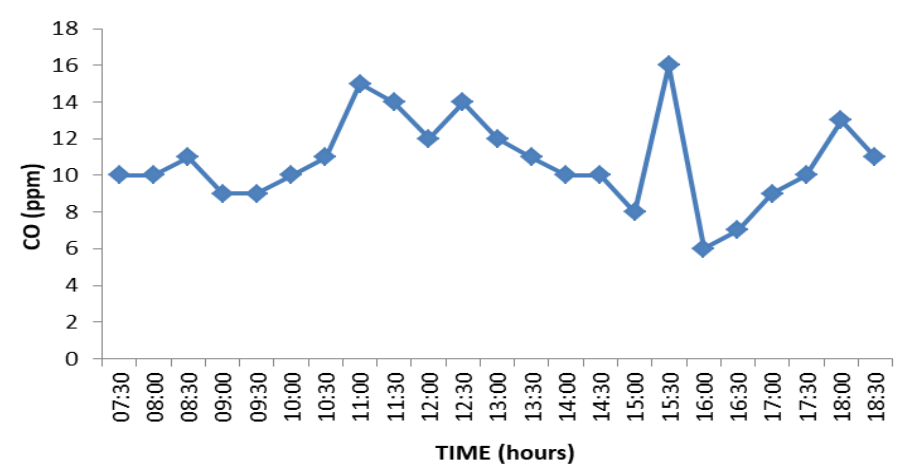

Figure 7. Sample Chart depicting the Hourly Variation of Carbon Monoxide levels at Peenya - an Industrial Area; on a Random Day.

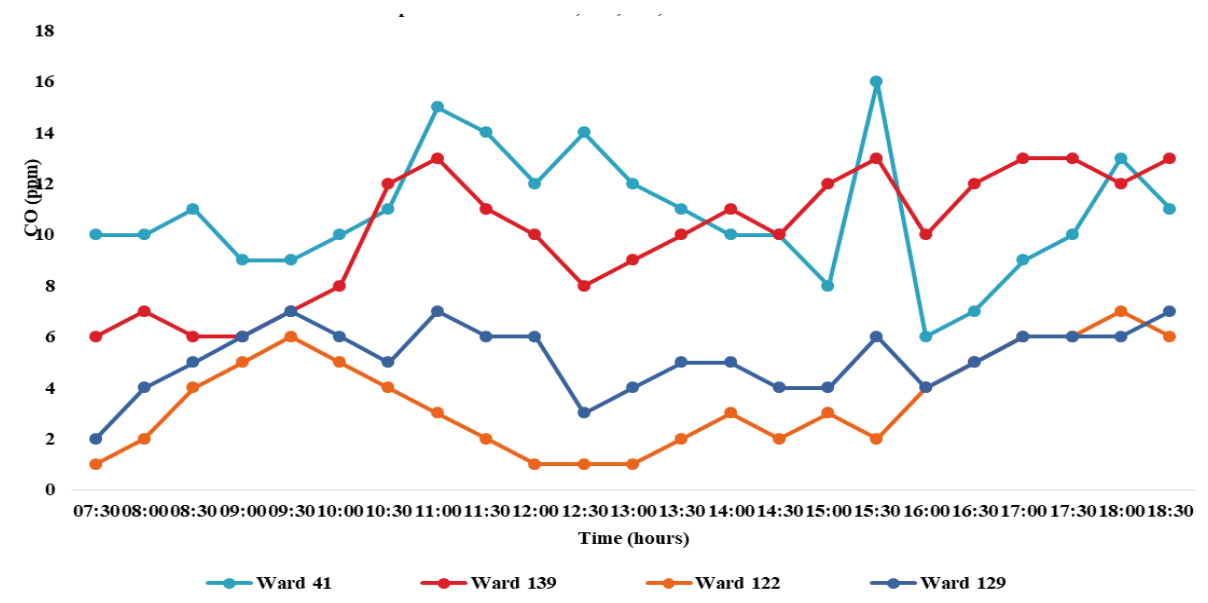

Figure 8. Sample Chart presenting the Comparison of Wards 41,139,122, 139 and depicting the Hourly Variation of Carbon Monoxide levels, on a Random Day. 


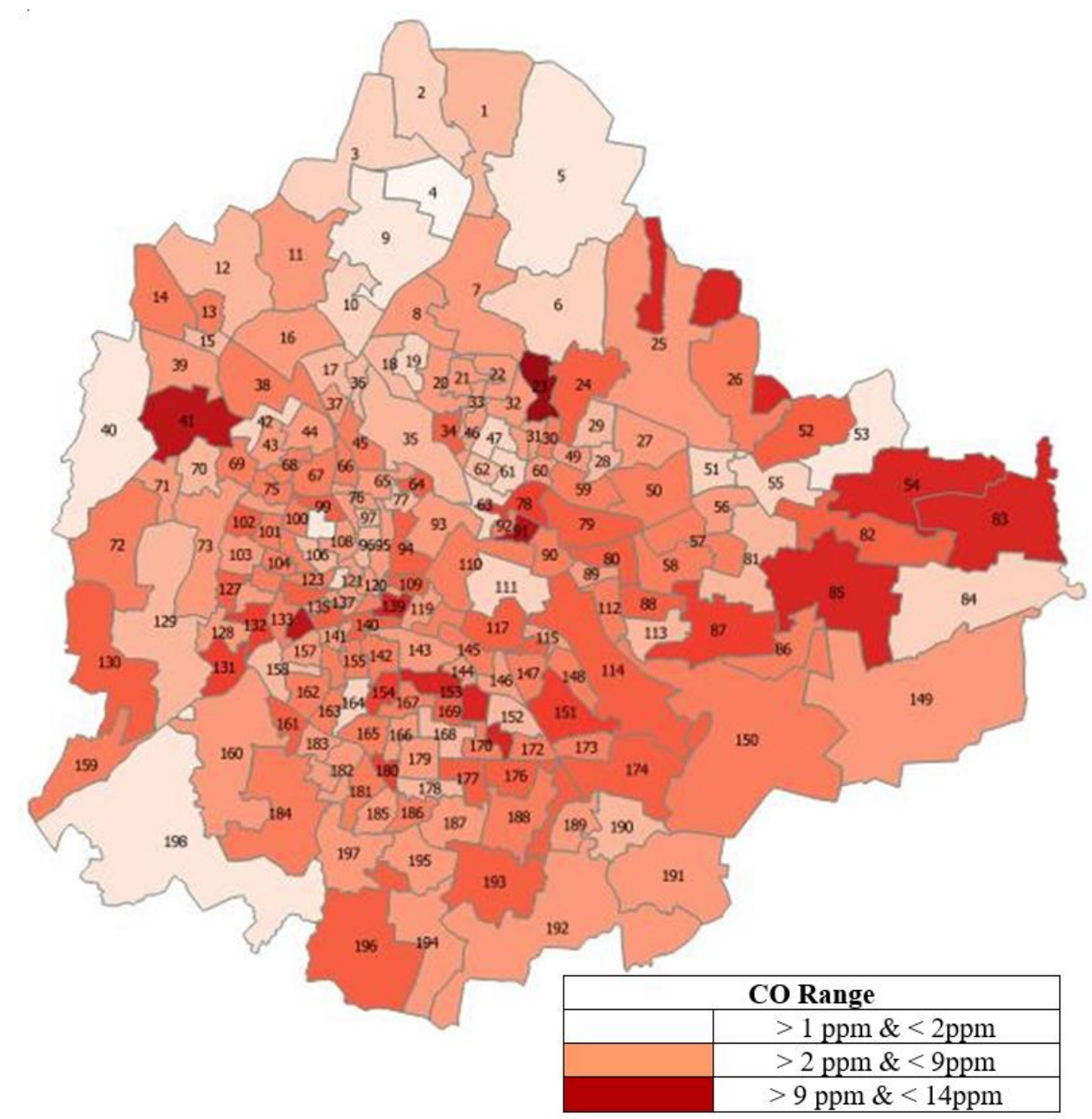

Figure 9. Delineation of observatories, based on hourly averaged mean values of CO for all the 198 wards.

Considering NAQQS (J.S. Kamyotra and D. Saha, 2011) as reference in the Indian Context, the following observations can be highlighted for the 198 wards of Bengaluru. While 1 ward with negligible-to-low vehicular movement was observed to be in the range of $>1 \&<2 \mathrm{ppm}$, around 185 wards were in the range of $>2 \&<9 \mathrm{ppm}$ owing to moderate-to-high traffic congestion. The remaining 12 wards were having severe traffic congestion were in the high-risk range of $>9 \&<14 \mathrm{ppm}$ that could lead to congestive heart failure.

Focusing upon individual non-isolated observations, startling violations of more than 202 instances were observed w.r.t. N.A.A.Q.S., US.E.P.A. and W.H.O., wherein 'CO' levels were found to thrive beyond $9 \mathrm{ppm}$, thereby risking the potential of increasing threats of congestive heart failure in the regular users of these lanes. Three Violations were found to exceed $15 \mathrm{ppm}$, which could shorten time to angina response and vigilance decrement (W.H.O. 2000). About 19 wards were 'most-critical' as more than $50 \%$ of their observations exceeded 9 ppm. These included Koramangala, Nayandahalli, Chikpet, Whitefield, KR Puram etc. Among these wards, while Koramanagala and Nayandahalli presented commercial land-use areas, the rest belonged to Industrial land-use areas. However it is Ward 41 (Peenya Industrial Area) which is most Severely Critical with about 19 of 23 observations being beyond 9 ppm. The least CO levels were found to be about 1 
and 2 ppm in the Residential wards such as Vidyaranyapura and Yelahanka Satellite Town respectively.

Upon compilation of all observations at all the 198 wards, it was found that 20 observations exceeded $17 \mathrm{ppm}, 50$ observations exceeded $15 \mathrm{ppm}, 200$ observations exceeded $14 \mathrm{ppm}$, and 356 observations exceeded $9 \mathrm{ppm}$. The highest lethal concentration was observed as 19 ppm in Nagavara and $18 \mathrm{ppm}$ in Manyata Tech Park Entrance. Both of these observatories represented commercial land-use areas with heavy vehicular movement. It is most indicative that the road users and dwellers will be prone to impaired performance in time discrimination and decrease in absolute exercise time (W.H.O. 2000). The major concerns from the aforementioned highlights the probable health risks for traffic personnel's/volunteer/s manning and posted at the junctions. This hence warrants urgent action to inculcate safety and remedial directives viz. policy redrafting and legal measures to attain a sustainable $\mathrm{CO}$ level management measures. Both preventive and corrective measures have to be implemented at user by policy makers. The study has identified and recommended the same specifically for each ward/observatory. However the discussion of it is beyond the scope of this draft. A brief overview of this includes real-time monitoring of $\mathrm{CO}$ at traffic junctions that has to be coordinated based on vehicular density-signal timings, and conversion of double lane entry into one-way entry to avoid slow moving traffic and congestions etc.

The preventive measures can be based on incentive based policy decisions that enhances usage of carpooling, public transport systems, dedicated bus/cycle/rickshaw lanes, time based dynamic management at places of public interest etc. Uphill sloped roads use as for downhill sloped traffic movement and banning of 2 stroke and $>20$ years old vehicles on road also significantly reduces $\mathrm{CO}$ accumulation. These aforementioned remarks are in lieu with deontological ethics. However, this can be effective only when awareness is created among all stakeholders. Essentially since preventive measures have been advocated in this research, thereby its morality is bound to overcome the consequences of wrong action causing $\mathrm{CO}$ pollution.

\section{Conclusions}

The outcome of study showcases details of violations of ambient $\mathrm{CO}$ concentration at the different wards of Bengaluru. Out of the 198 wards, $0.4 \%$ was in the low-risk range of $>1 \&<2$ ppm i.e. 'normally' safe. $93.6 \%$ were in the moderate-risk range of $>2 \&<9$ ppm but leading to fringes of 'maximum allowable concentration' i.e. beyond 'relatively' safe. Remaining $6 \%$ were in the high-risk range of $>9 \&<14 \mathrm{ppm}$. A deontological approach encompassing Preventive Measures (rather than Corrective Measures) would serve benevolence to all stakeholders. The major recommendations include $5 \%$ of the overall wards to be provided with traffic signals, enhancement of road width at $2.6 \%$ of the overall wards, expansion of green cover at $22.4 \%$ of the overall wards. Lastly via motivation and facilitation to reduce usage of private vehicles dwellers/users at $70 \%$ of the overall wards viz. promotion of public transport systems. 


\section{Future Scope of Study}

The present study was restricted to only winter and summer months. How-ever, the 'averaged' resultant CO concentration would not be similar throughout the year. Especially, it would be on a lower side during monsoon seasons. Hence, further studies are warranted that can encompass all the seasons, and throughout the year.

\section{References}

1. Aftab Jahan Begum, Rajesh Gopinath et al., 2021, Impact of Chaotic Urbanisation on Bengaluru's (India) Urban Avian Diversity, Transylvanian Review of Systematical and Ecological Research-The Wetlands Diversity, 23 (1), 81-94 p, ISSN 2344 - 3219. DOI: https://doi.org/10.2478/trser-2021-0007

2. Aftab Jahan Begum, Rajesh Gopinath, 2017, Development of Step-Wise Ranking for In-door Plants as Indoor Air Pollutant Purifiers, Annals of Faculty Engineering Hunedoara, 15 (4), 53-56 p. ISSN: 1584-2673.

3. Aftab Jahan Begum, Rajesh Gopinath, 2014, A Novel and Simpler Approach for Ranking of Indoor Air Pollutants, International Journal of Emerging Technologies in Computational and Applied Sciences, 7 (4), 342-344 p. ISSN: 2279-0055.

4. Carbon Monoxide poisoning, 2012, DSG FS-3522 04/2012 OSHA programs, policies or standards, Title 29 of the Code of Federal Regulations.

5. Chapter 5.5: Carbon monoxide Air Quality Guidelines, 2000, WHO Regional Office for Europe, Copenhagen, Denmark. Second Edition, 1-15 p.

6. Criteria for a Recommended Standard: Occupational Exposure to Carbon Monoxide, 2014, DHHS (NIOSH) Publication Number. 73-11000.

7. Deepak DG, Rajesh Gopinath, 2017, A Site-based practical Improvisation for the Analytical Determination of Aspect Ratio, Architecture and Engineering, 2 (3), 11-20 р. Эл № ФC77-70026. https://doi.org/10.23968/2500-0055-2017-2-3-11-20

8. Fathima Samana S, Rajesh Gopinath, 2012, Tracing the Impact of Bangalore's Urbanisation on its wetlands with a case study of Sampangi Lake, International Journal of Environment, Ecology, Family and Urban Studies, 2 (4), 23-28 p.

9. Harinath, Murthy $U, 2010$, Spatial distribution mapping for air pollution in industrial areas -A Case Study, Journal of industrial pollution control, $26(2), 217-220 \mathrm{p}$.

10. https://affordablehousing.live/bangalore-master-plan-2015.html

11. https://maps-bangalore.com/bengaluru-india-map

12. https://www.mapsofindia.com/custom-maps/city-ward-boundary-map.html

13. JS Kamyotra, D Saha, 2011, Guidelines for the Measurement of Ambient Air Pollutants, Central Pollution Control Board-Ministry of Environment \& Forests, Govt. of India.

14. Kanakiya RS, Singh SK, Shah U, 2015, GIS application for spatial and temporal analysis of the air pollution in urban area, International Journal of Advanced Remote Sensing and GIS, 4 (1), 1120-1129 p. ISSN: 2320-2043.

15. N Balasubramanya, Rajesh Gopinath, 2017, Historical Trend of Ambient Air Quality Indices at Key Observatories for Major Cities in Karnataka, India, Bulletin of Volgograd State University of Architecture and Civil Engineering, Series: Construction and Architecture, 49 (68), 189-195 p. ISSN 1815-4360, PI FS77-19321.

16. P.R. Bhanumurthy, Rajesh Gopinath, Vijayalakshmi Akella, 2014, Influence of Banga-lore's Canyon Geometry on the Intra-Urban Ambient Air Temperature, Scientific Herald of the Voronezh State University of Architecture and Civil Engineering, Construction and Architecture, 23 (3), 40-50 p. ISSN: 2075-0811.

17. Vijayalakshmi Akella, Rajesh Gopinath, P.R. Bhanumurthy, 2015, Parametric study of heat island effect due to urban sprawl in Bangalore, PhD Thesis, Jawaharlal Nehru Technological University, Anantapuram, http://hdl.handle.net/10603/46778 
18. Rajesh Gopinath et al., 2017, Real-Time Thermal Mapping for Heat and Cool Archipelagos of Bengaluru, India, Civil and Environmental Engineering, 13 (2), 106-111 p. ISSN 2199-6512. https://doi.org/10.1515/cee-2017-0014

19. Rajesh Gopinath et al., 2020, Real-Time Isohume Mapping for Cool and Warm Humidity Isles of Bengaluru City, Present Environment and Sustainable Development, 14 (1), 265-275 p. ISSN 2284-7820. https://doi.org/10.15551/pesd2020141021

20. Raub JA, Mathieu-Nolf, M, Hampson NB, Thom SR, 2000, Carbon monoxide poisoning - a public health perspective, Toxicology, 145 (1), 1-14 p.

21. Review of National Ambient Air Quality Standards for Carbon Monoxide, 2011, Part II Environmental Protection Agency 40 CFR Parts 50, 53 and 58, Final Rule, 76 (169) 54294 Federal Register.

22. Sachin S, Rajesh Gopinath et al., 2020, Real-Time Isohume Mapping for Cool and Warm Humidity Isles of Bengaluru City, Present Environment and Sustainable Development, 14 (1), 266-275 p, DOI: https://doi.org/10.15551/pesd2020141021

23. Suryati, H Khair, 2017, Mapping air quality index of carbon monoxide in Medan city, IOP Conference Series: Materials Science and Engineering, 180, 1-6 p.

24. TR Oke, 2006, Guide To Meteorological Instruments and Methods of Observation, Switzerland: Secretariat Of The World Meteorological Organization, Chapter 1, 1-22 p.

25. Yateen Lokesh, Rajesh Gopinath et al., 2017, Real Time Noise Violation Mapping from Road Traffic Network for Entire Bangalore City, Bulletin of Civil Engineers, 60 (1), 177-181 p., Saint-Petersburg, Russia, ISSN 1999-5571.

26. Vinod BR, Rajesh Gopinath et al., 2020, Analysis of E-Waste Ceramics as a Fine Aggregate for Rigid Pavements for Replacement of M-Sand and River Sand, Recent Developments in Waste Management-. Lecture Notes in Civil Engineering, 57. 385-396 p. ISBN 978-981-15-0989-6M. DOI: https://doi.org/10.1007/978-981-15-0990-2 31

27. Vrinda T, Rajesh Gopinath et al., 2018, Artificial Neural Network trained 'Simultaneous Extent Analysis' as a Logical Tool in Computation of Urban Heat Island Intensity, Science and Technology Asia, 23 (4), 18-22 p. ISSN 2586-9027. https://doi.org/10.14456/scitechasia.2018.28 